Article

\title{
Plug-in-Hybrid Vehicle Use, Energy Consumption, and Greenhouse Emissions: An Analysis of Household Vehicle Placements in Northern California
}

\section{Brett Williams *, Elliot Martin, Timothy Lipman and Daniel Kammen}

Transportation Sustainability Research Center (TSRC), University of California, Berkeley, 2150 Allston Way \#280, Berkeley, CA 94704, USA; E-Mails: elliot@berkeley.edu (E.M.); telipman@berkeley.edu (T.L.); kammen@berkeley.edu (D.K.)

* Author to whom correspondence should be addressed; E-Mail: bdw@berkeley.edu; Tel.: +1-510-642-4501; Fax: +1-510-665-2128.

Received: 7 December 2010; in revised form: 21 January 2011 / Accepted: 2 March 2011 / Published: 4 March 2011

\begin{abstract}
We report on the real-world use over the course of one year of a nickel-metalhydride plug-in hybrid - the Toyota Plug-In HV—by a set of 12 northern California households able to charge at home and work. From vehicle use data, energy and greenhouse-emissions implications are also explored. A total of 1557 trips-most using under 0.5 gallons of gasoline-ranged up to 2.4 hours and 133 miles and averaged 14 minutes and 7 miles. 399 charging events averaged 2.6 hours. The maximum lasted 4.6 hours. Most recharges added less than $1.4 \mathrm{kWh}$, with a mean charge of $0.92 \mathrm{kWh}$. The average power drawn was under one-half kilowatt. The greenhouse gas emissions from driving and charging were estimated to be 2.6 metric tons, about half of the emissions expected from a 22.4-mpg vehicle (the MY2009 fleet-wide real-world average). The findings contribute to better understanding of how plug-in hybrids might be used, their potential impact, and how potential benefits and requirements vary for different plug-in-vehicle designs. For example, based on daily driving distances, 20 miles of charge-depleting range would have been fully utilized on $81 \%$ of days driven, whereas 40 miles would not have been fully utilized on over half of travel days.
\end{abstract}

Keywords: plug-in hybrid; electric drive; charging; energy use; greenhouse gas emissions; household driving behavior; real world data; alternative fuel; battery size; fuel consumption 


\section{Introduction}

The world's major automakers are developing plug-in vehicles as part of their strategy to address efficiency, air-pollution, energy-security, greenhouse-gas, and other concerns held by regulators and consumers. Production of early offerings is already slated to be in the tens of thousands of vehicles in 2011, and, with several additional manufacturers planning to introduce models in 2012 and 2013, could exceed 100,000 soon. However, the assortment and degree of benefits realized by plug-ins, as well as the challenges their commercialization poses, depend on a number of factors. These include: vehicle design [1], adoption, and use, as well as recharging behavior and the nature and extent of available infrastructure. Analysis of data from real-world use of plug-in vehicles can contribute to a better understanding of their anticipated use and impact, and of how these vehicles might best be designed, charged, and otherwise prepared for by policymakers and strategic planners. Nevertheless, such data are still relatively scarce and usually based on the use of aftermarket conversions [2]. This study examines the real-world use over the course of a year of an early-generation, nickel-metalhydride (NiMH) plug-in-hybrid vehicle - the Toyota Plug-In HV-by a series of 12 California households able to charge both at home and work (but not elsewhere). It analyzes driving and charging behavior and calculates measures of energy consumption and greenhouse gas (GHG) emissions associated with the observed vehicle use.

Early experimental development of plug-in hybrids focused largely on vehicles with 50-150 miles (mi) of all-electric-range (AER) capability [3] and subsequent early theoretical analysis on designs with 20-60 AER [4]. More recently, analysis has suggested the early stages of plug-in-hybrid evolution efforts should focus on vehicles with an AER of 10 to $20 \mathrm{mi}$ rather than 30 to $40 \mathrm{mi}$ [5]. Like Williams and Lipman [6], this study focuses on plug-in hybrids with smaller batteries providing shorter charge-depleting (CD) ranges and operating in blended mode. Such vehicles promise to more economically provide fuel economy improvements (currently a more familiar metric to consumers than all-electric range) [7] and to require less powerful and capacious electric components [8] and less-costly-to-buy-and-operate recharging infrastructure. Axsen et al. [9] found, given a hypothetical choice, potential early adopters of plug-in hybrids in California opted for vehicle designs with the lowest $C D$ range. In their exercise, the base $C D$ range offered was 10 miles, with an option to purchase 20 miles for an additional $\$ 2,000$ or 40 miles of electric range for $\$ 4,000$. For these reasons smaller-battery, blended-mode plug-in hybrids may be more easily and widely commercialized and supported, particularly in the near-to-mid term.

The design of the vehicle driven for the study presented here is at the low end on the spectrum of battery size and CD range (see Section 2.1). Indeed, it should be noted that the most current Toyota Plug-In HV, a plug-in version of the Prius utilizing 5.2 kilowatt-hours (kWh) of lithium-ion (Li-ion) batteries, is purported to roughly double the nominal miles of CD range [10]. Uniquely, then, this study explores this less-charted end of the analysis spectrum. In doing so, it also creates a perspective on the starting point of an innovation trajectory that builds up to plug-in vehicles from what exists commercially today (the successful Toyota Prius), concordant with the way successful innovations tend to build on continuous origins $[11,12]$.

The data for this analysis were collected as part of an interdisciplinary research collaboration, the California Clean Mobility Partnership (CCMP). The CCMP was funded through California Assembly 
Bill 1811's incentive program for alternative fuels, managed by the California Air Resources Board (CARB) and the California Energy Commission (CEC), along with cost share from Toyota Motor Engineering \& Manufacturing North America, Inc. (TEMA) and Toyota Motor Sales' Advanced Technology Group (TMS). The overall research team included the University of California (Berkeley and Irvine), CARB, TEMA, and TMS.

Households selected for the project participated for three months, consecutively driving a hybrid (Toyota Prius), a plug-in hybrid (Toyota Plug-In HV), and then a fuel-cell SUV (Toyota FCHV-adv) for four weeks per vehicle. In addition to the vehicle operation data described in this study, data were collected from focus groups, surveys, interviews, GPS systems, and user logs to inform other attitudinal, behavioral, technical, economic, and environmental/energy assessments, as well as policy and educational message development.

\section{Methodology}

\subsection{Vehicle}

This study analyzes a dataset provided by Toyota to UC Berkeley's Transportation Sustainability Research Center (TSRC) based on information collected from the vehicle CAN-Bus of the Toyota Plug-In HV used in the CCMP. The Toyota Plug-In HV is different from a Prius because it adds charging capability and a second nickel-metal-hydride $(\mathrm{NiMH})$ battery for increased electric drive and a total of $2.6 \mathrm{kWh}$ of storage [13], as described in Table 1. The vehicle was one of the first manufacturer-provided plug-in hybrids available for study. Unlike third-party conversions, which had limited access to proprietary vehicle control systems and thus altered driving behavior, this vehicle was able to drive more often using battery power, as evidenced by fewer engine starts and overall higher all-electric speed capability.

Table 1. Differences between the Toyota Plug-In HV and Toyota Prius (adapted from [14,15]).

\begin{tabular}{lll}
\hline & Toyota Plug-In HV Used in CCMP Study & Toyota Prius Hybrid \\
\hline Mass & $1360 \mathrm{~kg}$ & $1260 \mathrm{~kg}$ \\
EV drive range & Nominally $\sim 6-\mathrm{mi}$, full charge $[16]$ & Brief periods at low speeds \\
EV mode max. speed & $\sim 62 \mathrm{mi} / \mathrm{h}$ & $\sim 20 \mathrm{mi} / \mathrm{h}$ under light throttle \\
Propulsion battery & $6.5 \mathrm{Ah} \times 2=13 \mathrm{Ah}(2.6 \mathrm{kWh}) \mathrm{NiMH}$ & $6.5 \mathrm{Ah}$ \\
Peak power capacity & $100 \mathrm{~kW}$ & $81 \mathrm{~kW}$ \\
Charging time & $\sim 3-4 \mathrm{~h}(110 \mathrm{~V}), \sim 1-1.5 \mathrm{~h}(220 \mathrm{~V})$ & $\mathrm{n} / \mathrm{a}$ \\
\hline
\end{tabular}

\subsection{Household Placements}

Households selected for the project participated for three months, consecutively driving a hybrid (Toyota Prius), a plug-in hybrid (Toyota Plug-In HV), and then a fuel-cell SUV (Toyota FCHV-adv) for four weeks per vehicle. Household selection was constrained by a number of practical factors. Access to hydrogen fueling was a primary constraint for placement. It was determined that households would fuel at the California Fuel Cell Partnership (CaFCP) in West Sacramento. Centralized recruitment through an employer or building corporation was chosen to facilitate recruitment and the provision of workplace vehicle charging for the plug-in vehicles. 
In addition to proximity to the $\mathrm{CaFCP}$, candidate organizations were required to:

- have secure parking for the study vehicles;

- be willing to install a 120 -volt (V), outlet with a 15 -ampere (A) breaker in a shaded location for charging of the plug-in when parked at the work location; and

- have management that was receptive to the study and willing to send study recruitment material to their employees.

After interviewing potential study host organizations, Raley's Family of Fine Stores corporate headquarters in West Sacramento met all of the requirements and management was enthusiastic about the project. About 500 employees received the recruitment email inviting them to participate in the study.

Driver selection included screening the drivers for a number of attributes, including:

- a good driving record;

- a $120-\mathrm{V}$ outlet with a $15-\mathrm{A}$ breaker for home charging;

- secure, outdoor but off-street parking and a round-trip commute distance of 50 miles or less for the Toyota FCHV-adv;

- successful completion of a driving evaluation;

- understanding of the responsibilities and requirements for driving non-commercially available vehicles; and

- agreement to participate in all of the data collection aspects of the research-including the surveys, exit interview, drive log, and providing gas receipts and electricity bills.

One additional household member was allowed to drive the study vehicles and participate in the study in addition to the primary driver recruited through the company participant. There were a total of 18 drivers.

The sample of drivers is small from a statistical perspective, and was drawn from employees of a corporate headquarters. When compared to the population of California 18 years or older, as characterized by the 2006-2008 American Community Survey [17], the sample differs in some notable ways. Table 2 compares the distribution of gender, age, income, and education. As a group, the sample reflects upper-income, middle-class, working Americans. About $60 \%$ of the sample was female in comparison to the population's even split. Study participants were mostly of working age. The sample did not contain any college-age participants or participants over the age of 64 . The distribution of respondent education is skewed slightly toward higher education levels. Finally, the household income of respondents was on balance far higher than the general population: $84 \%$ of households made more than $\$ 75,000$ a year. Thus, the sample appears to have the means and several other characteristics that might make it more suitable for early plug-in-vehicle market participation than the California population as a whole.

\subsection{Dataset}

The dataset analyzed here characterizes each of 2113 logged driving (1676) or charging (437) events in northern California from May 2009 into May 2010. Variables used include: start date, start time, duration (s), distance traveled (mi), gasoline used (gal), and battery energy used (kWh), from 
which several other quantities are calculated and modeled. Two segments of data-6/24/09 thru 07/03/09 and 01/24/10 thru 02/04/10 — were found to be unintentionally overwritten and are missing from this analysis.

Table 2. Demographics of study drivers and the California population*.

\begin{tabular}{|c|c|c|}
\hline Demographic Attribute & Sample & California Population \\
\hline Gender & $\mathrm{N}=18$ & $\mathrm{~N}=27,043,417$ \\
\hline Male & $38.9 \%$ & $49.6 \%$ \\
\hline Female & $61.1 \%$ & $50.4 \%$ \\
\hline Age Category & $\mathrm{N}=18$ & $\mathrm{~N}=27,043,417$ \\
\hline $18-24$ & $0 \%$ & $14 \%$ \\
\hline $25-34$ & $13 \%$ & $19 \%$ \\
\hline $35-44$ & $25 \%$ & $20 \%$ \\
\hline $45-54$ & $50 \%$ & $19 \%$ \\
\hline $55-64$ & $13 \%$ & $13 \%$ \\
\hline $65-74$ & $0 \%$ & $8 \%$ \\
\hline 75 or over & $0 \%$ & $7 \%$ \\
\hline Total & $100 \%$ & $100 \%$ \\
\hline Education & $\mathrm{N}=18$ & $\mathrm{~N}=27,043,417$ \\
\hline Did not complete high school & $6 \%$ & $20 \%$ \\
\hline High school graduate & $11 \%$ & $24 \%$ \\
\hline Some college & $28 \%$ & $23 \%$ \\
\hline 2-year college degree & $11 \%$ & $7 \%$ \\
\hline 4-year college Degree & $33 \%$ & $17 \%$ \\
\hline Graduate Degree & $11 \%$ & $9 \%$ \\
\hline Other & $0 \%$ & $0 \%$ \\
\hline Total & $100 \%$ & $100 \%$ \\
\hline Income (Households, \$ US) & $\mathrm{N}=12$ & $\mathrm{~N}=12,177,852$ \\
\hline Less than $\$ 10,000$ & $0 \%$ & $5 \%$ \\
\hline$\$ 10,000$ to $\$ 25,000$ & $0 \%$ & $14 \%$ \\
\hline$\$ 25,000$ to $\$ 35,000$ & $0 \%$ & $9 \%$ \\
\hline$\$ 35,000$ to $\$ 50,000$ & $8 \%$ & $13 \%$ \\
\hline$\$ 50,000$ to $\$ 75,000$ & $8 \%$ & $18 \%$ \\
\hline$\$ 75,000$ to $\$ 100,000$ & $25 \%$ & $13 \%$ \\
\hline$\$ 100,000$ to $\$ 150,000$ & $42 \%$ & $15 \%$ \\
\hline More than $\$ 150,000$ & $17 \%$ & $13 \%$ \\
\hline Total & $100 \%$ & $100 \%$ \\
\hline
\end{tabular}

* California population estimates are from the U.S. Census Bureau's 2006-2008 American Community Survey [17].

\subsection{Energy Demand Profiles}

Electricity and gasoline demand profiles are constructed for each day of the week by summing calculated average power entries in one-minute blocks. Average power is calculated by dividing the actual energy used (kWh of either gasoline or electricity) over the entire event (driving or charging episode) by the duration of the event (in h). This implicitly makes the simplifying assumption that 
charging or gasoline consumption occurred at a constant, average rate throughout a given event [18]. Gasoline usage is computed relatively directly, whereas the battery-energy-used data is adjusted in sign and multiplied by a factor (1/0.83) to reflect an assumed constant charger efficiency of $83 \%$, roughly similar to Lemoine et al. [19].

\subsection{Greenhouse-Gas Estimation}

Emissions from gasoline demand are computed following Axsen et al.'s [9] 2010 use of 86 grams of fuel-cycle carbon-dioxide-equivalent $\left(\mathrm{gCO}_{2} \mathrm{e}\right)$ greenhouse gases (GHGs) assigned to each megajoule (MJ) of gasoline [20] - 67 grams (g) for fuel combustion [21] and $19 \mathrm{~g}$ for upstream emissions [22].

The consumer electricity demand profile described in Section 2.4 is increased by an additional 7\% to account for transmission and distribution losses (a common rule-of-thumb). Thus, every kWh of electricity consumed in vehicle operation is assumed to require $1.29(=1.07 / 0.83) \mathrm{kWh}$ of electricity generation. California power-plant emission factors are then assigned to compute emissions from electricity demand. This is done using three methods reflective of 2010 California emissions: (1) using an average of total state emissions (403 $\mathrm{gCO}_{2} \mathrm{e} / \mathrm{kWh}$ ) [9], (2) using a 2010-average of marginal state emissions ( $\left.626 \mathrm{gCO}_{2} \mathrm{e} / \mathrm{kWh}\right)$ [23,24], and (3) using a matrix of marginal 2010 rates that vary by hour of day and month [24] to match with charging times. The marginal rates, both that averaged over the year into a single value and those in matrix form by day and month, are as modeled by EDGE-CA, a merit-order dispatch model of generation on the California grid in 2010 that includes firm and system imports of power from neighboring states [24].

\section{Results and Discussion}

\subsection{Vehicle Use}

\subsubsection{Driving Behavior}

Table 3 summarizes the driving data for the set of 1557 trips, after excluding 119 zero-distance, presumably "key-on only" events from a total of 1676 events. Trips ranged up to 2.4 hours (h) and 133 miles (mi), but on average were a dozen minutes long and covered about $7 \mathrm{mi}$.

Table 3. Driving behavior summary.

\begin{tabular}{lccc}
\hline $\mathbf{N}=1557$ & Start Date & Duration (h) & Distance (mi) \\
\hline Total & & 362 & 11,309 \\
\hline Min. & $5 / 5 / 09$ & 0.001 & 0.00002 \\
Mean & & 0.2 & 7.3 \\
Max. & $5 / 3 / 10$ & 2.4 & 133 \\
\hline
\end{tabular}

\subsubsection{Daily Driving and Battery Size}

Table 4 and Figure 1 describe total daily driving distance and its distribution by the day of the week and distance. The information on the driving patterns of the study sample contained in Figure 1 is further detailed in Table A-1 (in the appendix). Figure 1 also includes labels for three distances consistent with CD ranges of interest: $10 \mathrm{mi}$ (90\% of all driving days exceeded this distance), $20 \mathrm{mi}$ 
(81\%), and $40 \mathrm{mi}(47 \%)$. In addition to excluding zero-distance or "invalid" driving events-as in Tables 3.1-1 and A-1-Table 4 and Figure 1 exclude zero-travel days. In other words, they examine only those days on which the vehicle was driven. More distance was covered on weekdays, generally over $30 \mathrm{mi} /$ day and averaging $35 \mathrm{mi} /$ day, as compared to weekends, which averaged $21 \mathrm{mi} /$ day. However, some of the longest-distance days were observed on the weekends.

Table 4. Percentage of days exceeding a given daily driving distance ( $\%$ of days, travel days only).

\begin{tabular}{rrrrrrrrrr}
\hline Miles & Sunday & Monday & Tuesday & Wednesday & Thursday & Friday & Saturday & Weekday & All \\
\hline $\mathbf{0}$ & $100 \%$ & $100 \%$ & $100 \%$ & $100 \%$ & $100 \%$ & $100 \%$ & $100 \%$ & $100 \%$ & $100 \%$ \\
$\mathbf{1}$ & $76 \%$ & $98 \%$ & $100 \%$ & $96 \%$ & $98 \%$ & $100 \%$ & $90 \%$ & $98 \%$ & $95 \%$ \\
$\mathbf{1 0}$ & $61 \%$ & $89 \%$ & $100 \%$ & $96 \%$ & $98 \%$ & $100 \%$ & $73 \%$ & $96 \%$ & $90 \%$ \\
$\mathbf{2 0}$ & $42 \%$ & $86 \%$ & $95 \%$ & $91 \%$ & $85 \%$ & $98 \%$ & $53 \%$ & $91 \%$ & $81 \%$ \\
$\mathbf{3 0}$ & $30 \%$ & $68 \%$ & $84 \%$ & $80 \%$ & $70 \%$ & $80 \%$ & $47 \%$ & $77 \%$ & $68 \%$ \\
$\mathbf{4 0}$ & $24 \%$ & $48 \%$ & $50 \%$ & $51 \%$ & $53 \%$ & $56 \%$ & $37 \%$ & $51 \%$ & $47 \%$ \\
$\mathbf{5 0}$ & $24 \%$ & $23 \%$ & $25 \%$ & $31 \%$ & $20 \%$ & $29 \%$ & $30 \%$ & $26 \%$ & $26 \%$ \\
$\mathbf{6 0}$ & $21 \%$ & $2 \%$ & $18 \%$ & $16 \%$ & $15 \%$ & $17 \%$ & $23 \%$ & $14 \%$ & $16 \%$ \\
$\mathbf{7 0}$ & $15 \%$ & $2 \%$ & $14 \%$ & $9 \%$ & $10 \%$ & $10 \%$ & $17 \%$ & $9 \%$ & $10 \%$ \\
$\mathbf{8 0}$ & $15 \%$ & $0 \%$ & $9 \%$ & $7 \%$ & $8 \%$ & $2 \%$ & $17 \%$ & $5 \%$ & $8 \%$ \\
$\mathbf{9 0}$ & $9 \%$ & $0 \%$ & $7 \%$ & $4 \%$ & $0 \%$ & $2 \%$ & $17 \%$ & $3 \%$ & $5 \%$ \\
$\mathbf{1 0 0}$ & $9 \%$ & $0 \%$ & $5 \%$ & $4 \%$ & $0 \%$ & $2 \%$ & $13 \%$ & $2 \%$ & $4 \%$ \\
$\mathbf{1 2 5}$ & $3 \%$ & $0 \%$ & $2 \%$ & $0 \%$ & $0 \%$ & $2 \%$ & $7 \%$ & $1 \%$ & $2 \%$ \\
$\mathbf{1 5 0}$ & $0 \%$ & $0 \%$ & $0 \%$ & $0 \%$ & $0 \%$ & $2 \%$ & $7 \%$ & $\sim 0 \%$ & $1 \%$ \\
$\mathbf{1 8 0}$ & $0 \%$ & $0 \%$ & $0 \%$ & $0 \%$ & $0 \%$ & $0 \%$ & $0 \%$ & $0 \%$ & $0 \%$ \\
\hline
\end{tabular}

It is important to note that our sample of drivers is not necessarily representative of the general population (though they may be more representative of early adopters, as described in Section 2.2). For example, they were screened for having one-way commutes less than 50 miles, to be sufficiently close to hydrogen refueling for their third vehicle placement. Keeping this in mind, and in order to compare these study observations with the driving behavior of the general population, Figure 1 also illustrates a similar distribution of daily driving distances derived from the 2009 National Household Travel Survey (NHTS) [25]. The NHTS is a large, nationwide travel survey that collects a single day of travel data from each respondent, including total miles driven. Hence, it does not characterize the longitudinal profile of national driving, but rather a large cross-section $(\mathrm{N}=181,051)$ of people who drove on the day that they were sampled. The NHTS profile presented here consists only of the distance driven during the day that they were sampled. Thus it does not include zero-distance or non"car" travel days. (However, each observation has been rebalanced using the trip weights provided with the NHTS dataset.) 
Figure 1. Percentage of days exceeding a given total driving distance (travel days only).

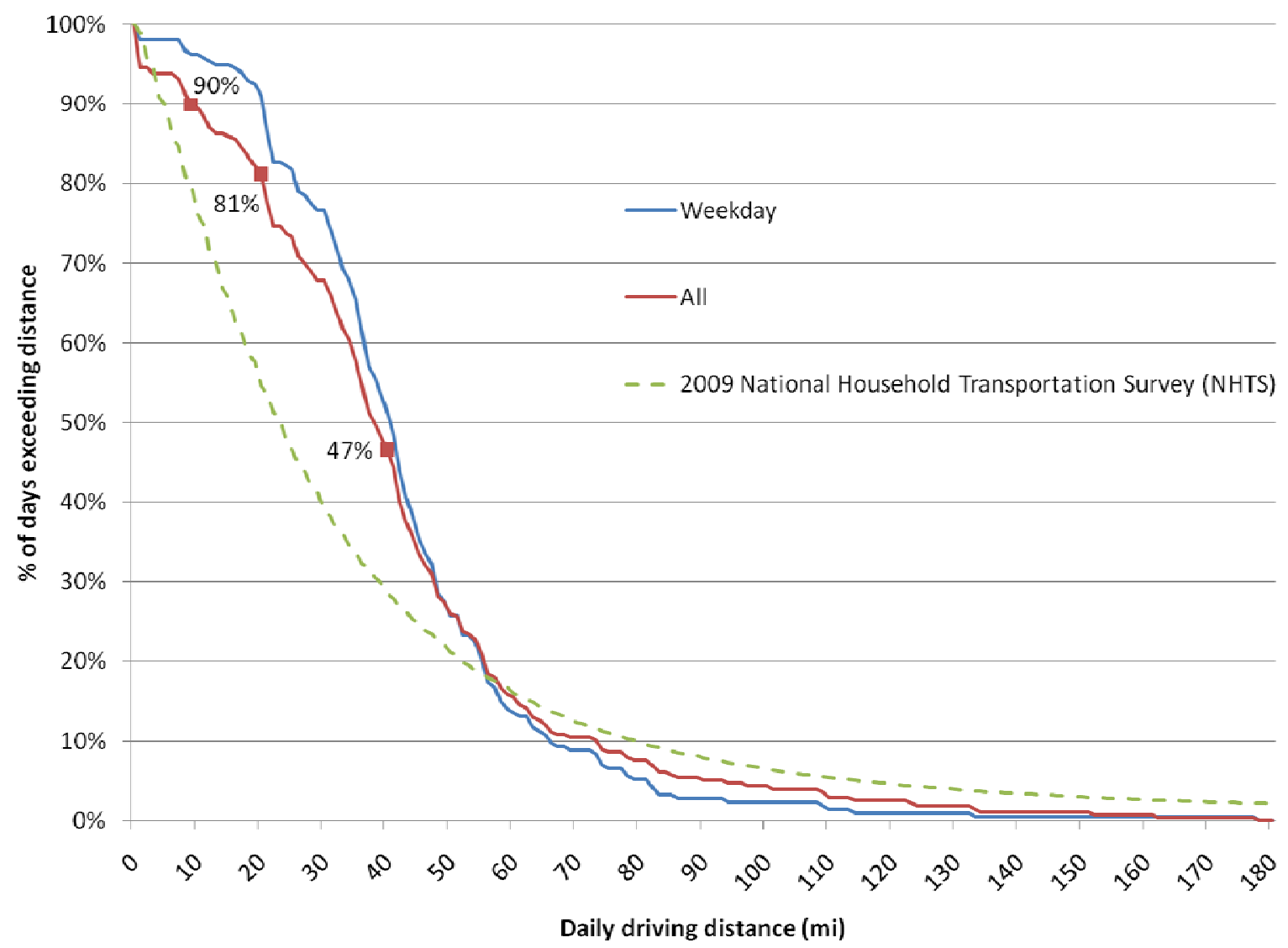

As illustrated in Figure 1, about $72 \%$ of all respondents sampled in the 2009 NHTS exceeded 10 miles on the day they were sampled and $50 \%$ exceeded 20 miles. It should be noted that long-distance trips can diminish the advantages of plug-ins, emphasizing the importance of those trips. However, compared to the NHTS, the study sample had a significantly larger percentage of days exceeding nearly all distances up to about 60 miles, and only a somewhat lower percentage of days exceeding distances greater than 60 miles. Thus, they had daily driving requirements that would have exhausted CD ranges of particular interest (e.g., 10-50 miles) more frequently.

For vehicle designers, Table A-1 and Figure 1 also give some insight as to how fully utilized the battery might be. For example, based on the sample, to assure that the expensive battery asset is fully utilized on at least $81 \%$ of the days it was driven by the study participants, the battery should be designed to provide no more than 20 miles of $\mathrm{CD}$ range. Further, this is roughly twice the distance required for similarly full utilization by the larger NHTS sample. Similarly, based on the study sample, on about half of the days driven, a 40-mi CD range would not be fully utilized.

\subsubsection{Charging Behavior}

Table 5 and Figure A-2 summarize the charging data for the set of 399 charging events. This excludes 38 non-charging events from a total of 437 events - presumably attempts where the vehicle went into charging mode but the battery did not experience a net charge (e.g., the charging cord was plugged into car but not the wall). Charging events lasted as long as 4.6 hours, but, on average, were a little over two-and-one-half hours [26]. 
Table 5. Charging behavior summary.

\begin{tabular}{lcc}
\hline $\mathbf{N}=399$ & Start Date & Duration (h) \\
\hline Total & & 1036 \\
\hline Min. & $5 / 5 / 09$ & 0.005 \\
Mean & & 2.6 \\
Max. & $5 / 3 / 10$ & 4.6 \\
\hline
\end{tabular}

Table 6 and Figure 2 describe the percentage of the number of charging events and their distribution by the day of the week and time. The percentage of charging events is found by dividing the count of charging events that occurred during the specified minute on a given day of the week by the total number of charging events for that day of the week. On weekdays, the largest overall mass or "mountain" of charging events occurred between $6 \mathrm{pm}$ and 3am, peaking around roughly $7 \mathrm{pm}$ to $11 \mathrm{pm}$. The second-biggest mass of charging events, presumably highly influenced by the availability of workplace charging, happened between 6am and noon, peaking between roughly 8am to 10am. A third, "after lunch" peak, occurred between roughly 1 or $2 \mathrm{pm}$ and $5 \mathrm{pm}$. Compared to the EPRI/NRDC charging profile that assumes three-quarters of charging occurs nominally off-peak (10pm to 6am) [27], this profile (unconstrained by peak pricing) exhibits much of its charging in the early evening before $10 \mathrm{pm}$ and an earlier, bigger, and partially bimodal (before and after lunch) daytime peak.

Figure 2. Percentage of charging events by time and day: (a) weekdays and (b) weekends.

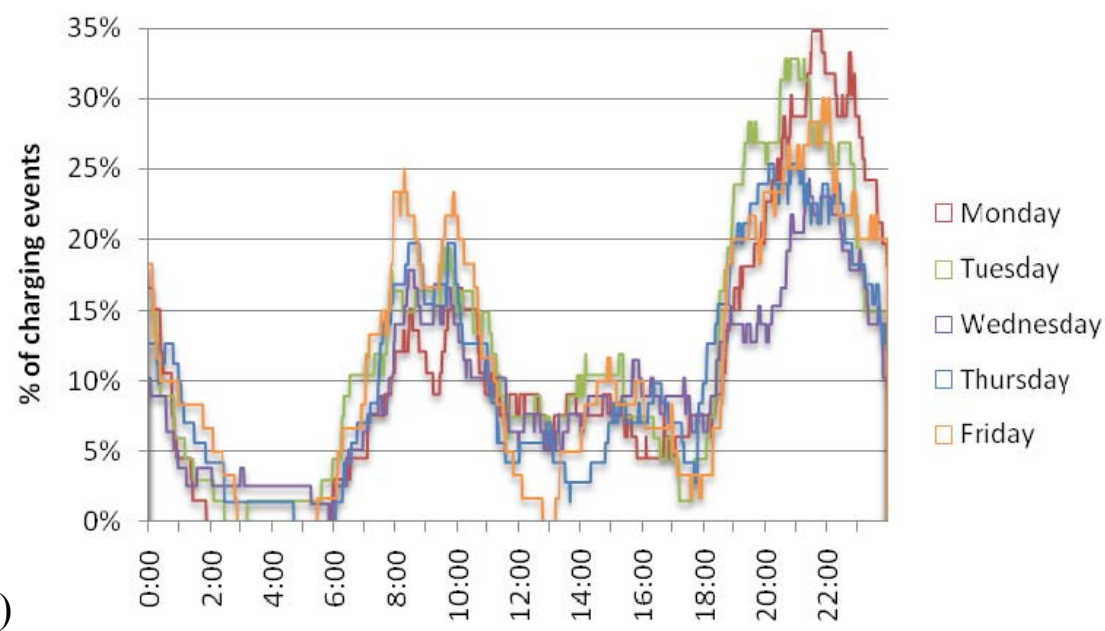

(a)

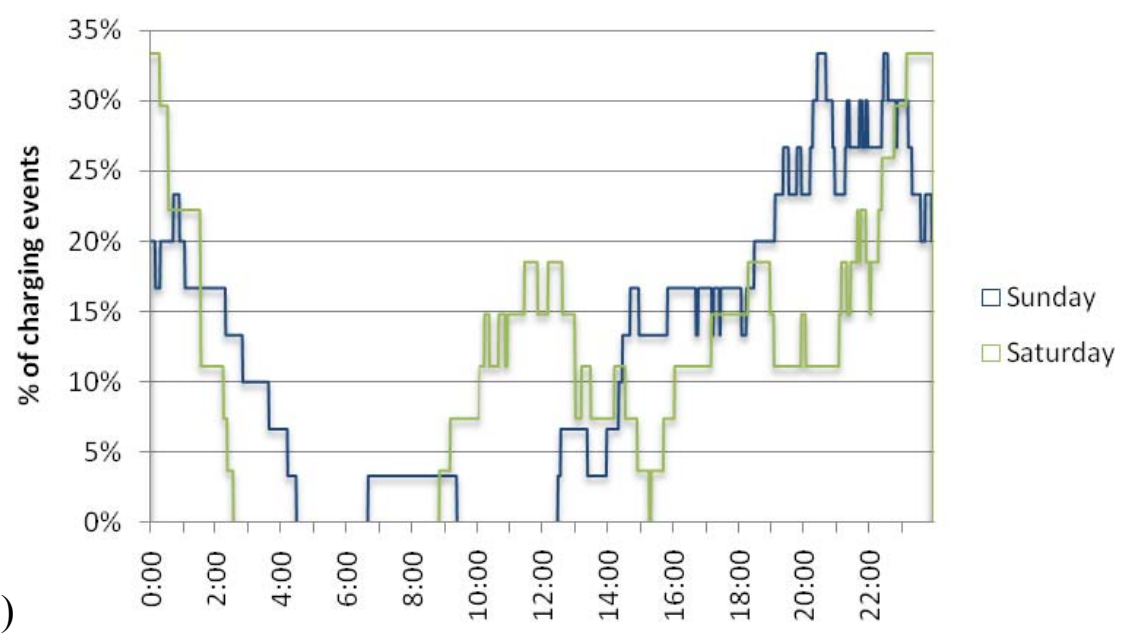


Table 6. Percentage of charging events (\%).

\begin{tabular}{rrrrrrrrrr}
\hline & Sunday & Monday & Tuesday & Wednesday & Thursday & Friday & Saturday & Weekday & All \\
\hline Ave. & $12.0 \%$ & $10.7 \%$ & $11.7 \%$ & $9.6 \%$ & $10.4 \%$ & $11.2 \%$ & $11.0 \%$ & $10.7 \%$ & $10.9 \%$ \\
\hline
\end{tabular}

Weekend charging days differ from weekday charging trends and from each other. For example, the daytime charging peak starts later, as might be expected. In round numbers, on Saturdays a "single" daytime peak spans roughly $9 \mathrm{am}$ to $5 \mathrm{pm}$ and peaks around $11 \mathrm{am}$ to $1 \mathrm{pm}$; on Sunday it largely starts after noon, peaks after $2 \mathrm{pm}$, and spans into the evening charging peak, which, as with weekdays, starts taking effect around $6 \mathrm{pm}$. Saturday evening charging is more spread out and dips to a local minimum between $9 \mathrm{pm}$ and $11 \mathrm{pm}$.

\subsection{Energy Use}

\subsubsection{Driving Energy Use}

Table 7 summarizes driving energy for the set of 1557 trips. Most events used less than one-half gallon of gasoline. Average power ( $\mathrm{kW}$ of gasoline demanded) is calculated as described in Section 2.4 and used in subsequent calculation of GHG distributions from driving (see Section 3.3.1).

Table 7. Driving energy summary.

\begin{tabular}{lcc}
\hline N=1557 & Gasoline Used (gal) & $\begin{array}{c}\text { Ave. Gasoline Demand } \\
\text { (kW of Gasoline) }\end{array}$ \\
\hline Total & 225 & \\
\hline Min. & 0 & 0 \\
Mean & 0.1 & 15 \\
Max. & 2.7 & 57 \\
\hline
\end{tabular}

Dividing total gasoline used by total distance traveled, the average fuel consumption for this specific set of vehicle observations is $0.66 \mathrm{kWh}$ gas $/ \mathrm{mi}$. This ignores the electrical charging energy used, and including that contribution (see below), the overall average energy use is roughly $0.70 \mathrm{kWh} / \mathrm{mi}$.

\subsubsection{Fuel Economy by Driving Distance}

Figure 3 depicts gasoline fuel economy by trip distance. Part (a) shows all trips that used gasoline. Part (b) is a magnification along both axes of (a). It shows that the most extreme variability and influence of plugging in is largely gone for trips longer than roughly 10 miles (e.g., trip-to-trip differences greater than $75 \mathrm{mi} /$ gal fall to the more modest, though still considerable variation seen in hybrids and as a function of varying driving conditions). Part (c) includes fully electric trips and explores their distribution by magnifying the short trip distances. It depicts 236 fully electric trips. Unlike aftermarket conversions, all-electric operation of the study vehicle lasted for the entire multiple-mile trip in several cases without the vehicle engine turning on (e.g., if triggered when the all-electric power or energy-storage capabilities had been exceeded, or possibly for other reasons unknown to the authors). The longest observed entirely electric trip [28] was about 5.2 miles. 
However, most $(73 \%)$ of the entirely electric trips observed were less than one quarter of a mile in length, as seen in Figure 4. This is expected because the vehicle was not designed to maximize provision of fully electric trips or even of all-electric range, but rather uses computer optimization to manage electric operation within the context of its charge-depleting, blended-mode operation. Additionally, it should be noted that the Raley's headquarters building is located next to a highway, and the return commute of drivers may have included routine hard accelerations shortly after starting.

Figure 3. Gasoline fuel economy by trip distance: (a) for trips that used gasoline; (b) magnification; (c) detail including fully electric trips (note: electric trips have undefined $\mathrm{mi} / \mathrm{gal}$ ).

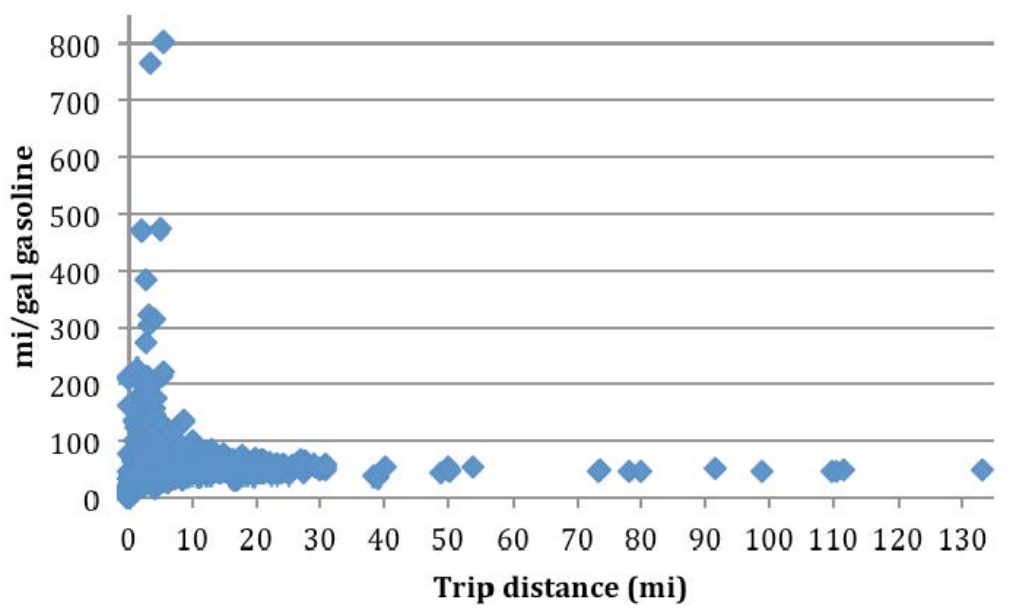

(a)

Trip distance (mi)

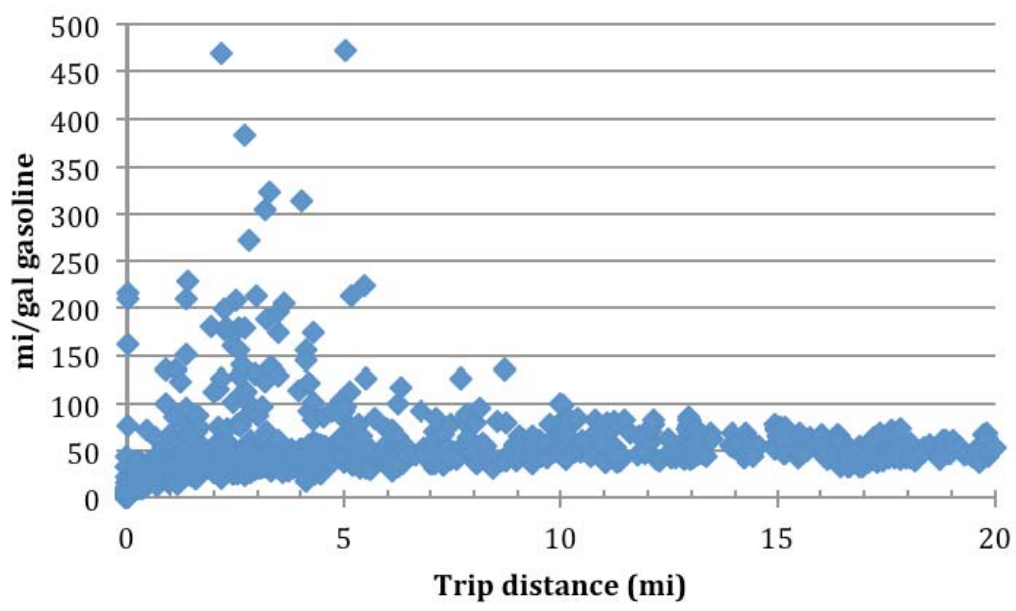

(b)

Trip distance (mi)

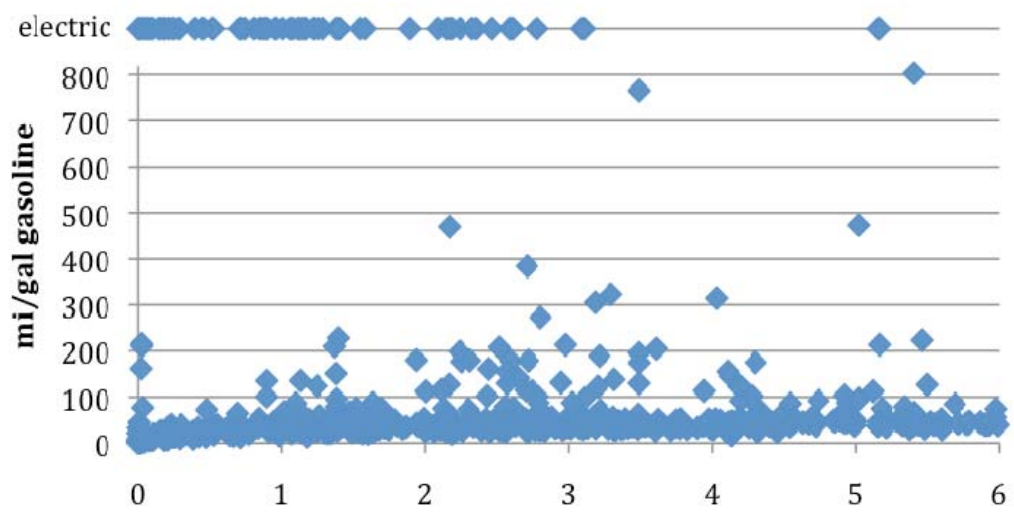

(c)

Trip distance (mi) 


\subsubsection{Charging Energy Use and Comparison}

Table 8 and Figure A-3 summarize the charging energy use for the set of 399 charging events. "Battery energy used" is defined as negative for charging events. The largest recharge observed added $1.67 \mathrm{kWh}$ to the battery, $64 \%$ of a $2.6-\mathrm{kWh}$ battery pack. Most of the recharges observed, however, added less than $1.4 \mathrm{kWh}$, and the mean charge $0.92 \mathrm{kWh}$, or about $35 \%$ of a $2.6-\mathrm{kWh}$ pack. Though no data is available describing the instantaneous charging power, the average power drawn from the $120-\mathrm{V} / 15-\mathrm{A}$ circuits the vehicle was allowed to plug into was less than one-half of one kilowatt. This assumes an $83 \%$ charging efficiency, and is calculated by dividing the energy used during a given event by the duration of that event as described in Section 2.4. This is quite modest relative to the requirements facing utilities should battery EVs and/or fast charging become prevalent.

Table 8. Charging energy summary.

\begin{tabular}{lcc}
\hline $\mathbf{N}=399$ & Battery Energy Used (kWh) & Ave. Power (kW) \\
\hline Total & -367 & \\
\hline Min. & -1.7 & 0.003 \\
Mean & -0.9 & 0.4 \\
Max. & -0.0004 & 0.8 \\
\hline
\end{tabular}

Figure 4. All-electric trips exceeding a given trip distance (\%).

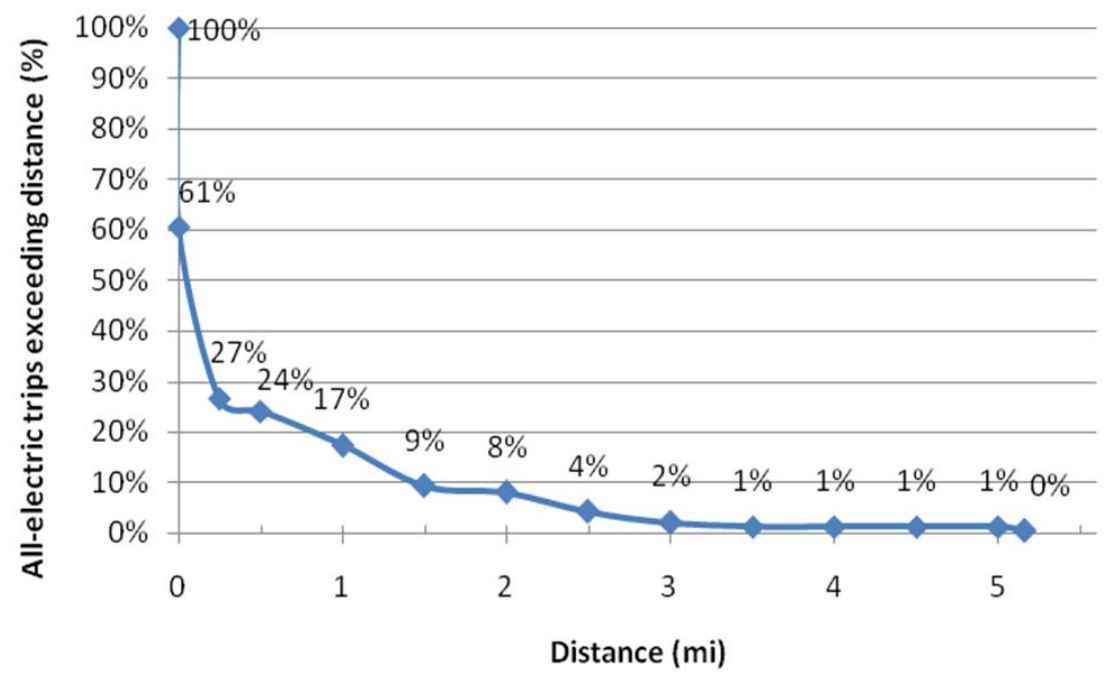

Table 9 estimates the total charging energy demanded over the course of the study (minus lost data) and its distribution by the day of the week. Despite a slightly lesser percentage of charging events on weekdays (Table 6), substantially more total charging was done on weekdays, as might be expected with availability of workplace charging.

Table 9. Total charging energy demanded * by day $(\mathrm{kWh})$.

\begin{tabular}{|c|c|c|c|c|c|c|c|c|c|c|}
\hline & Sunday & Monday & Tuesday & Wednesday & Thursday & Friday & Saturday & Weekday & Weekend & All \\
\hline Total & 39 & 72 & 80 & 76 & 73 & 69 & 31 & 371 & 70 & 441 \\
\hline
\end{tabular}

* Note: includes all available data from one vehicle over 12 months; charging energy $=-$ (battery energy used)/(charging efficiency), i.e., $441=-(-367) \times 0.83$, with rounding errors. 


\subsection{Greenhouse Gas (GHG) Emissions}

\subsubsection{Driving GHG Emissions}

Figure 5 shows the distribution of total GHG emissions from gasoline consumption by the time of day and day of the week. Although the temporal distribution of greenhouse gases, which have more of a global impact, is less important than that of criteria air pollutants, which act more locally, these temporal characterizations are also included to provide additional illustration of the overall driving impact. As noted in the methodology discussion, 86 grams (g) of fuel-cycle carbon-dioxide-equivalent ( $\mathrm{gCO} 2 \mathrm{e}$ ) GHGs are assigned to each megajoule (MJ) of total gasoline demand [20] $-67 \mathrm{~g}$ for fuel combustion [21] and $19 \mathrm{~g}$ for upstream emissions [22].

Figure 5. Total driving GHG emissions by time and day of week: (a) weekdays; (b) weekends.

(a)
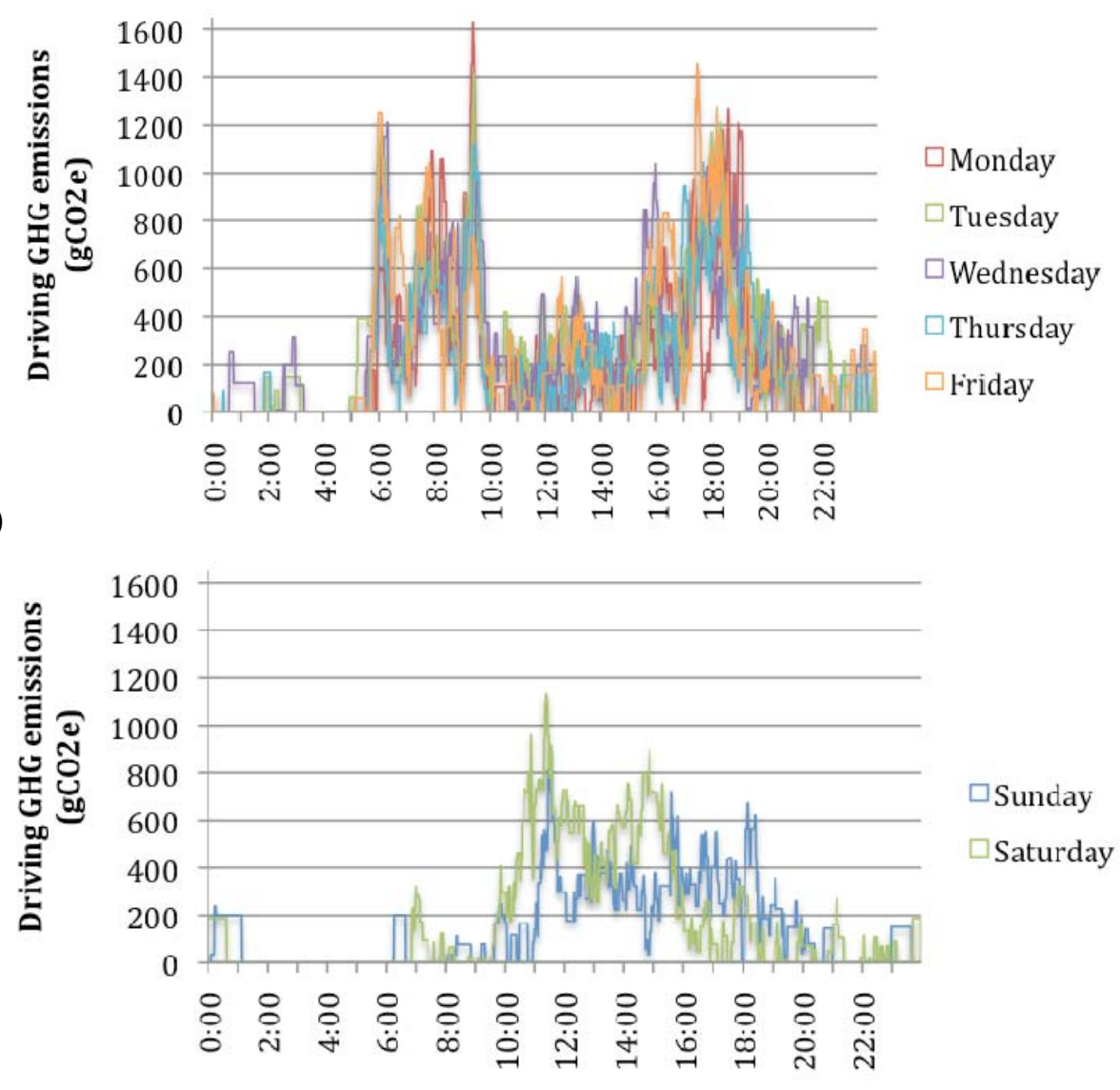

\subsubsection{Charging GHG Emissions and Comparisons}

Figure 6 compares charging emissions to driving emissions by time of day over one selected weekday (Wednesdays). Charging emissions are assigned $626 \mathrm{gCO}_{2} \mathrm{e} / \mathrm{kWhe}$ [24], representative of 2010 California marginal power-plant emissions as described in the methodology section. Note that this is very similar to the rate assigned to a new 2010 simple-cycle gas turbine by EPRI/NRDC, $628 \mathrm{gCO}_{2} \mathrm{e} / \mathrm{kWhe}$ - [27]. For comparison, Shiau et al. [29] use $690 \mathrm{~g} / \mathrm{kWh}$ as a U.S. average (and 9\%, rather than $7 \%$, transmission loses). 
Table 10 compares GHG emissions from charging calculated from the electricity demand observations using three methods: one "average" and two "marginal" methods. It also summarizes overall GHG findings.

Figure 6. Total GHG emissions by time of day: charging and driving.

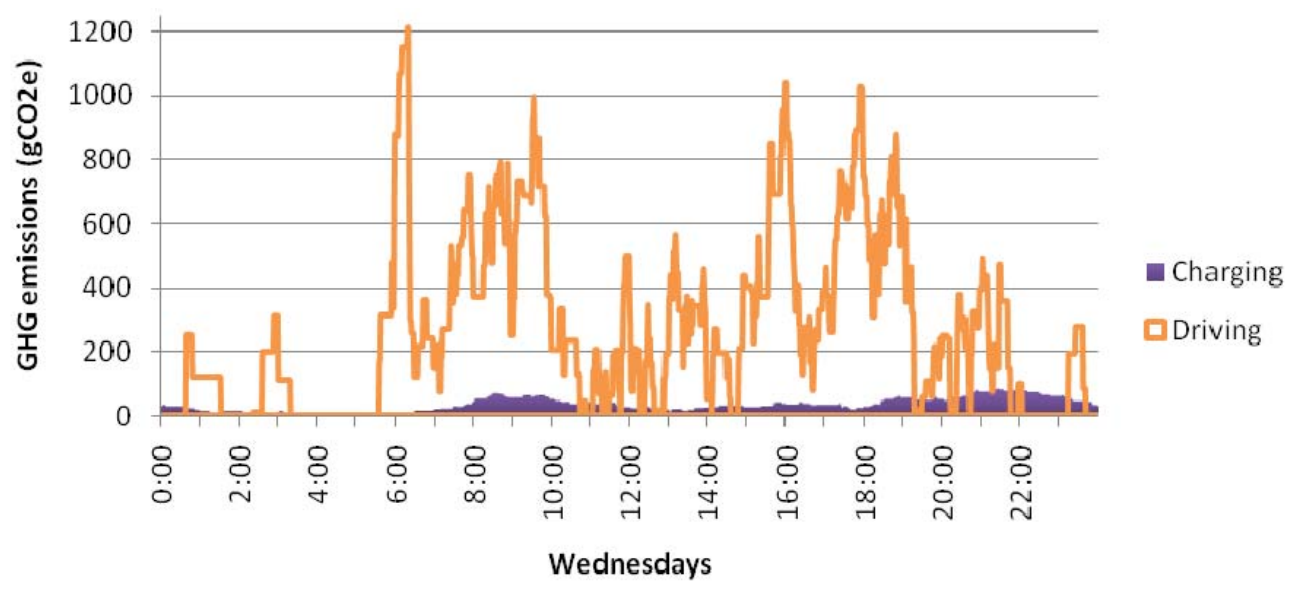

Table 10. GHG emissions summary.

\begin{tabular}{lll}
\hline $\mathbf{M g C O}_{2} \mathbf{e}$ & Based on Observations of: & Assumptions \\
\hline 2.258 & Gasoline demand & $86 \mathrm{~g} / \mathrm{MJ}$ gasoline (fuel-cycle) [20] \\
0.190 & Electricity demand & $403 \mathrm{~g} / \mathrm{kWh}$ electricity ("2010 average") [9] \\
0.296 & Electricity demand & $626 \mathrm{~g} / \mathrm{kWh}$ electricity ("2010 marginal”) [24] \\
0.309 & Electricity demand & 2010 marginal rates as a function of month \\
& & and hour [24] \\
2.554 & Gasoline \& electricity demand & $86 \mathrm{~g} / \mathrm{MJ}$ gasoline, 626 g/kWh electricity \\
5.2 & Driving distances & $22.4 \mathrm{mpg}$ "real-world” MY2009 fleet-wide \\
& & economy [30] \\
\hline
\end{tabular}

Table 10 indicates that study participants produced roughly 2.6 metric tons of GHGs over the course of their 11,309 miles of driving, or roughly $226 \mathrm{~g} / \mathrm{mi}$, including emissions estimated from use of both gasoline and 2010 marginal California electricity. Note that $226 \mathrm{~g} / \mathrm{mi}$ is roughly equivalent to the rate estimated by EPRI/NRDC for plug-in hybrids with 20-mile all-electric-range (PHEV20s) being charged by 2010 new gas turbines, as depicted in Figure 5-1 of their 2007 analysis [27]. Although PHEV20s were characterized as achieving $37.9 \mathrm{mpg}$ in charge sustaining mode (i.e., when the all-electric range was depleted) and thus might be considered slightly larger or less efficient than the Prius platform [31], in previous related studies, even compact PHEV20s are estimated to require batteries greater than $5 \mathrm{kWh}$ in capacity [4]. Similarly, Shiau et al.'s "minimum cost" all-electric plug-in hybrid was found to be a PHEV20 with a $5.4 \mathrm{kWh}$ battery, and emitting $7.92 \mathrm{~kg} /$ day $\times 300$ days $=2.38$ metric tons per year [29].

Table 10 also indicates that had study participants instead achieved the U.S. EPA's "real-world" fleet-wide average fuel economy for model-year-2009 vehicles over the distance driven during the study, they would have produced roughly twice as much GHG. It is important to note that this potential difference results from several compounded factors, including not just the incremental improvements 
of the plug-in technology but also from the comparison of a specific vehicle type to a sales-weighted representative average of all passenger-vehicle types. An additional desirable comparison would of course be between the study vehicle and a Toyota Prius. However, although the participants were asked to assess a Prius via the survey portion of the larger study, the Prius driven by the study participants could unfortunately not be equipped to provide the same data analyzed here. Further, precision limitations in the comparison described above of the plug-in vehicle's observed demand with estimates based on study distances and average fuel economies grow more acute as the comparison gets tighter and unfortunately do not allow meaningful comparison with an "average" Prius.

\section{Summary \& Conclusions}

\subsection{Study Context}

Analysis of data from real-world use of plug-in vehicles - still relatively rare due to limited vehicle availability and nascent vehicle and infrastructure design — can contribute to a better understanding of their anticipated use and impact. This study examines the real-world use over 12 months of an early-generation, nickel-metal-hydride plug-in-hybrid vehicle by a series of 12 California households able to charge at home and work.

Plug-in hybrids with smaller batteries providing shorter charge-depleting (CD) ranges and operating in blended mode may be more easily and widely commercialized and supported, particularly in the near-to-mid term (see Section 1). The vehicle driven for the study was one of the first manufacturer-provided plug-in hybrids available for study and is at the low end on the spectrum of battery size and CD range-lower than the Prius Plug-in Hybrid Vehicle (Prius PHV) using lithium-ion batteries announced for availability in early 2012 [32] - creating a perspective on the starting point of an innovation trajectory that builds up to plug-in vehicles from what exists commercially, concordant with the way successful innovations tend to build on continuous origins $[11,12]$.

Determination of household placement location was constrained by a number of practical factors. Access to hydrogen fueling for a vehicle not analyzed here but part of the overall CCMP study, the Toyota FCHV-adv, was a key constraint for placement selection.

\subsection{Driving \& Charging Behavior}

The dataset analyzed here includes 2113 logged events (1676 driving and 437 charging events) in northern California from May 2009 into May 2010. There were 1557 trips covering 11,309 miles, excluding 119 zero-distance driving events. Trips ranged up to 2.4 hours and 133 miles long, but averaged 14 minutes and 7 miles. More total distance was covered on weekdays, generally over $30 \mathrm{mi} /$ day and averaging $35 \mathrm{mi} /$ day as compared to weekends, which averaged $21 \mathrm{mi} /$ day. However, some of the longest-distance days were observed on the weekends.

The findings suggest that for the expensive battery asset to be fully utilized on at least $81 \%$ of the days driven by the study participants - who had a higher percentage of travel days exceeding distances comparable to charge-depleting ranges of interest (10-50 miles) than the NHTS drivers illustrated in Figure 1 - the battery should be designed to provide no more than 20 miles of CD range. In contrast, on about half of the days driven, a 40-mi CD range would not be fully utilized. This is of course a very 
different optimization (maximizing utilization and minimizing size for affordability) than for an all-battery EV: if able to provide a full 100 miles of range (at several times the battery cost) EVs face the challenging prospect of not providing enough to fully cover all of the driving logged for our study participants - let alone their perceived range needs or desires - with accordant marketing and product re-definition challenges. This is not to say that those challenges are insurmountable or that one product definition or multifaceted business model is superior to another, but rather to simply highlight the distinctions between plug-in hybrids and battery EVs in this regard.

Charging events lasted as long as 4.6 hours, but, on average, were a little over two-and-one-half hours. In terms of the diurnal distribution of charging events, the biggest "mountain" of weekday charging events occurred between $6 \mathrm{pm}$ and $3 \mathrm{am}$, peaking between roughly $7 \mathrm{pm}$ to $11 \mathrm{pm}$. The second-biggest mass of charging events, presumably highly influenced by the availability of workplace charging, happened between 6am and noon, peaking between roughly $8 \mathrm{am}$ to $10 \mathrm{am}$. A third peak occurred roughly between $1 \mathrm{pm}$ and $5 \mathrm{pm}$.

\subsection{Energy Use}

Most trips used less than one-half gallon of gasoline. The mean gasoline consumption was 0.1 gallons (gal) per trip, whereas the maximum was 2.7 gal, and the total amount of fuel consumed was 225 gal. Dividing total gasoline used by total distance traveled, the average fuel consumption for this particular set of vehicle observations is $0.66 \mathrm{kWh}$ of gasoline per mi. Including total charging energy (i.e., total battery energy divided by 0.83 to account for charging losses), the overall average is $0.70 \mathrm{kWh} / \mathrm{mi}$. This implies that electricity consumption accounted for roughly $6 \%$ of the total energy used (gasoline plus electricity).

The extreme variability and influence of plugging in on fuel economy largely disappears for trips longer than roughly 10 miles (though the considerable variability seen for charge-sustaining hybrids of course remains). Unlike aftermarket conversions, all-electric operation lasted for the entire multiple-mile trip in several cases without the vehicle engine turning on. Nevertheless most (73\%) of the entirely electric trips observed were less than one quarter of a mile in length. This is expected, because the vehicle was not designed to maximize the provision of fully electric trips or even of all-electric range, but rather uses computer optimization to manage electric operation within the context of its charge-depleting, blended-mode operation. Further, hard accelerations may have been required at the beginning of many trips.

The largest observed charging event added $1.67 \mathrm{kWh}$ to the battery, $64 \%$ of the $2.6-\mathrm{kWh}$ battery pack. Most of the charging events observed, however, added less than $1.4 \mathrm{kWh}$, and the mean charge $0.92 \mathrm{kWh}$, or about $35 \%$ of a $2.6-\mathrm{kWh}$ pack. Though no data is available describing the instantaneous charging power, the mean average power drawn (as described in Section 3.2.2) was estimated to be less than one-half of one kilowatt - quite modest relative to the requirements facing utilities should battery EVs and/or fast charging become prevalent. Despite a slightly lower percentage of charging events, substantially more total charging was done on weekdays, as might be expected with the availability of workplace charging. 


\subsection{Greenhouse Gas (GHG) Emissions}

Emissions from charging were estimated to be a small fraction (12\%) of emissions from driving this study vehicle, as seen in Figure 6. Over time, however, the proportion of charging emissions will increase with the increased utilization of electric drive. Further, when assigning emissions to vehicle charging, policymakers face a difficult choice. For example, they can choose to assign rates reflective either of total power-plant operation averaged over the year or of marginal additions to the grid (emissions from the last power-plant(s) added to serve additional load). Charging load can currently be thought of as a marginal load in the sense that it is being added onto an existing electrical grid whose operation was planned for other reasons. Hence, the example in Figure 6 assigns a simplified marginal emissions rate (reflective of the last power-plants added, but assumed constant and averaged over the year). However, as charging becomes part of the planning process, assigning to charging load the full burden of the marginal emission rate is arguably over-burdening one type of load relative to another. Table 10 compares GHG emissions from charging calculated from the electricity demand observations using three methods: one "average" and two "marginal" methods. Emissions averaged approximately $226 \mathrm{~g} / \mathrm{mi}$ and were, in total, roughly half that of a conventional baseline.

\subsection{Key Findings}

Key findings from this study of the use of an early-generation, nickel-metal-hydride Toyota Prius Plug-in HV include:

- Study participants had a higher percentage of travel days exceeding key distances (10-50 miles) than the NHTS drivers illustrated in Figure 1.

- Nevertheless, for a plug-in hybrid's expensive battery asset to be fully utilized on at least $81 \%$ of the days driven by the study participants, the battery would need to be designed to provide no more than 20 miles of charge-depleting or "electric" range. In contrast, on about half of the days driven, a 40-mile charge-depleting range would not be fully utilized.

- With "unconstrained" [33] at-home and free workplace charging, this study observed earlier evening ( $6 \mathrm{pm}$ to midnight), additional daytime (6am to noon and, to a lesser extent, noon to $6 \mathrm{pm}$ ), and less nighttime (midnight to 6am) charging than assumed in some studies (e.g., [27]).

- The mean average power drawn for charging, estimated as described in Section 3.2.2, was less than one-half of one kilowatt. The maximum average power drawn was less than one kilowatt.

- The overall average fuel consumption for this particular set of vehicle observations is calculated to be 0.66 kilowatt-hours of gasoline per mile. Including charging, the overall average is estimated to be 0.70 kilowatt-hours per mile.

- The study participants were estimated to produce roughly 226 grams of GHGs per mile, including emissions from both gasoline (88\%) and California marginal electricity (12\%). Assuming California marginal electricity increases the contribution of charging by $56 \%$ relative to assuming California average electricity. 
As expected, the real-world use of a small-battery, blended-mode plug-in hybrid produces results distinct from, and with greater variation and complexity than, analysis of all-electric designs characterized with necessarily simplifying assumptions. For example, Shiau et al. [29] confine their scope "to the all-electric strategy for simplicity since blended-strategy operation characteristics are sensitive to control parameters," and their analysis reasonably treats battery depth-of-discharge as a simple function of driving distance, all-electric range as a simple function of battery capacity, and charge-depleting efficiency as constant. Real-world fuel economy of course exhibits considerable variability, as seen in Figure 3. In this case, the extreme variability of real-world fuel economy observations - enhanced by plugging in, charging, and then depleting charge via a complex control strategy - gives way to the less extreme but still considerable variability of regular hybrid operation as trips exceed roughly 10 miles.

The small-battery, blended-operation vehicle observed here used a relatively small amount of electricity. Electricity consumption accounted for roughly $6 \%$ of the total energy used (gasoline plus electricity) and emissions from charging are estimated to be roughly $12 \%$ of emissions estimated for driving the study vehicle. And the low power draw of this type of vehicle, estimated to average less than one kilowatt in this study, is comparable to other household appliances and significantly less than the likely requirements of battery EVs and fast charging. Nevertheless, the vehicle achieved, through a number of mechanisms, significant fuel-economy and GHG-emissions improvements. For example, the study vehicle was estimated to have averaged roughly half the emissions expected from a 2009 fleet-wide average vehicle, or a rate roughly comparable to previous analysis [4,27] of plug-in hybrids charged by similarly carbon-intensive electricity but largely at night and designed for 20 miles of all-electric range from batteries roughly twice the capacity (and thus cost).

\subsection{Directions for Future Research}

Additional research is needed analyzing driving and recharging patterns and their relationship to different plug-in-vehicle designs. Future analysis of the CCMP and subsequent vehicle placements could dig more deeply into dynamics related to the distance driven between charging and the electric contribution to driving range in small-battery blended-mode plug-in hybrids. It could also include more and different types of data and analysis - e.g., characterizing the use of the other study vehicle types, using attitudinal/behavioral data from surveys and interviews, and identifying trends in use over time to look for "waning novelty" or "increasing familiarity" effects. Further, investigation of additional topics related to plug-in-hybrid use could be informed by subsequent placements with enhanced data collection, such as how engine on/off events relate to criteria-air-pollutant impacts. Collaborations between analysts modeling and those deploying plug-in hybrids could establish particularly fruitful feedback loops to inform both lines of inquiry.

Collectively, this growing body of knowledge will create an increasing understanding of the anticipated use and impact of electric-drive vehicles, and of how these vehicles might best be designed, fueled, and otherwise prepared for by policymakers and strategic planners. 


\section{Acknowledgements}

TSRC would like to thank Craig Childers and Elise Keddie at California Air Resources Board, Bill Reinert, Jaycie Chitwood, and Craig Scott at Toyota Motor Sales, and Takehito Yokoo, Justin Ward, Vern Francisco, and Paul Howard at Toyota Motor Engineering \& Manufacturing North America, Inc. for support throughout the project. Particular thanks are due to the management and employees of Raley's Family of Fine Stores that participated in the focus groups and as drivers of the study vehicles. At UC Berkeley, Rachel Finson managed the vehicle placements and study implementation, assistance was provided by Jarrett Bato and Dana Goin, and Susan Shaheen was co-principal investigator for the CCMP team.

\section{References and Notes}

1. Independent of vehicle size, plug-in drivetrain design ranges through three major categories, from small-battery, blended-mode plug-in hybrids based on series-parallel gasoline-combustion hybrids such as the Toyota Prius PHV to range-extender series hybrids such as the Chevy Volt to allbattery electric vehicles (EVs) such as the Nissan LEAF.

2. Kurani, K.S.; Axsen, J.; Caperello, N.; Davies, J.; Stillwater, T. Plug-In Hybrid Electric Vehicle (PHEV) Demonstration and Consumer Education, Outreach, and Market Research Program. Technical Report for University of California at Davis: Davis, CA, USA, 30 June 2009.

3. Bradley, T.H.; Frank, A.A. Design, demonstrations and sustainability impact assessments for plug-in hybrid electric vehicles. Renewable Sustainable Energy Rev. 2009, 13, 115-128.

4. Duvall, M. Comparing the Benefits and Impacts of Hybrid Electric Vehicle Options for Compact Sedan and Sport Utility Vehicles. Technical Report, Electric Power Research Institute, Inc: Palo Alto, CA, USA, 2002.

5. Vyas, A.D.; Santini, D.J.; Johnson, L.R. Potential of Plug-In Hybrid Electric Vehicles to Reduce Petroleum Use: Issues Involved in Developing Reliable Estimates. Transp. Res. Rec. 2009, 2139, $55-63$.

6. Williams, B.D.; Lipman, T.E. Strategies for Transportation Electric Fuel Implementation in California: Overcoming Battery First-Cost Hurdles. Technical Report for California Energy Commission Public Interest Energy Research (PIER) Transportation Program: Sacramento, CA, USA, 2009.

7. DOE. FreedomCar and Vehicle Technologies Program Plug-In Hybrid Electric Vehicle R\&D Plan; U.S Department of Energy: Washington, DC, USA, 2007.

8. Markel, T.; Simpson, A. Plug-In Hybrid Electric Vehicle Energy Storage System Design. In Proceedings of The Advanced Automotive Battery Conference, Baltimore, Maryland, 17-19 May 2006.

9. Axsen, J.; Kurani, K.S.; McCarthy, R.; Yang, C. Plug-in Hybrid Vehicle GHG Impacts in California: Integerating Consumer-Informed Recharge Profiles with an Electricity-Dispatch Model; Technical Report for University of California at Davis: Davis, CA, USA, 2010. 
10. Abuelsamid, S. Toyota officially launches plug-in Prius program, retail sales in 2011. Available online: http://green.autoblog.com/2009/12/14/toyota-officially-launches-plug-in-prius-programretail-sales-i/ (accessed on 1 October 2010).

11. Williams, B.D. Commercializing Light-Duty Plug-In/Plug-Out Hydrogen-Fuel-Cell Vehicles: "Mobile Electricity" Technologies, Early California Household Markets, and Innovation Management. PhD Dissertation, University of California at Davis: Davis, CA, USA, 2007.

12. Hargadon, A. How Breakthroughs Happen: The Surprising Truth about How Companies Innovate; Harvard Business School Press: Boston, MA, USA, 2003; p. 254.

13. The authors take the $2.6 \mathrm{kWh}$ to be rated, not available, capacity.

14. Toyota Delivers Plug-in Prius to UC Irvine and UC Berkeley As Part of Clean Mobility Partnership. Available online: http://pressroom.toyota.com/Releases/View?id=TYT2007110961930 (accessed on 29 September 2010)

15. Wimmer, R. Opportunities and Challenges of PHVs: Plug-In Cars, Energy Security and Climate-American and European Perspectives; Toyota Motor North America: Washington, DC, USA, 2008.

16. This is of course highly subject to specific driving conditions.

17. 2006-2008 American Community Survey 3-Year Estimates, U.S. Census Bureau. Available online: http://www.census.gov/acs/www/ (accessed on 6 December 2010).

18. Note that although the data available required us to calculate and use a constant, average rate throughout a given event, the rates are not constant across all events (e.g., see Figure A-3b), providing more information than a uniformly constant rate assumption.

19. Lemoine, D.M.; Kammen, D.M.; Farrell, A.E. An innovation and policy agenda for commercially competitive plug-in hybrid electric vehicles. Environ. Res. Lett. 2008, 3, 1-8.

20. Samaras, C.; Meisterling, K. Life Cycle Assessment of Greenhouse Gas Emissions from Plug-in Hybrid Vehicles: Implications for Policy. Environ. Sci. Technol. 2008, 42, 3170-3176.

21. EPA. Inventory of U.S. Greenhouse Gas Emissions and Sinks: 1990-2004; Technical report for U.S. Environmental Protection Agency: Washington, DC, USA, April 2006.

22. Wang, M.Q. Development and Use of GREET 1.6 Fuel-Cycle Model for Transportation Fuels and Vehicle Technologies; Argonne National Laboratory: Argonne, IL, USA, 2001.

23. McCarthy, R.W. Assessing vehicle electricity demand impacts on California electricity supply. PhD Dissertation, University of California at Davis: Davis, CA, USA, 2009. Avaible online: http://proquest.umi.com/pqdweb?did=1987411791\&sid=1\&Fmt=2\&clientId=48051\&RQT=309\& VName $=$ PQD (accessed on 16 April 2010).

24. McCarthy, R.; Yang, C. Determining marginal electricity for near-term plug-in and fuel cell vehicle demands in California: Impacts on vehicle greenhouse gas emissions. J. Power Sources 2010, 195, 2099-2109.

25. 2009 National Household Travel Survey v2.0, Oak Ridge National Laboratory. Available online: http://nhts.ornl.gov/ (accessed on 15 November 2010). 
26. This average, however, may be slightly depressed by a number of very short charging events, as seen in Figure A-2. There does not appear to be a strong pattern to 15 such events shorter than 2.5 minutes (e.g., there are various intervals between charging events before and after, a reasonable average charging power was achieved given the duration, and they appear singly and in pairs and grouped with longer charging events), but we speculate that any human "fiddling" that might contribute would decrease over time. There is some mixed evidence for this in the data that may be explored in a future analysis.

27. EPRI; NRDC. Environmental Assessment of Plug-In Hybrid Electric Vehicles Volume 1: Nationwide Greenhouse Gas Emissions; Available online: http:/mydocs.epri.com/docs/ CorporateDocuments/SectorPages/Portfolio/PDM/PHEV-ExecSum-vol1.pdf (accessed on 1 March 2010).

28. Note the distinction between a fully electric trip (i.e., an entire driving event where the gasoline engine never turns on) and the concept of all-electric range, which may be a portion of a trip during which the vehicle operates without combustion.

29. Shiau, C.-S.N.; Kaushal, N.; Hendrickson, C.T.; Peterson, S.B.; Whitacre, J.F.; Michalek, J.J. Optimal Plug-In Hybrid Electric Vehicle Design and Allocation for Minimum Life Cycle Cost, Petroleum Consumption, and Greenhouse Gas Emissions. J. Mech. Des. 2010, 132, 091013-1-091013-11.

30. Shepardson, D. EPA: U.S. vehicle fuel efficiency hits record level. The Detroit News, 17 November 2010.

31. A common rule-of-thumb for real-world Prius fuel economy is $45 \mathrm{mpg}$ (in charge-sustaining mode_-its only mode).

32. Toyota Prius Family (2011). Available online: http://www.toyota.com/upcoming-vehicles/priusfamily/?srchid=K610_p372324288 (accessed on 20 January 2011).

33. Participants did have to pay for the additional electricity used at home over the course of their one-month placement, but were not subject to changes in utility rate structures, smart charging algorithms or other policy or technical constraints.

\section{Appendix}

Figure A-1. Driving duration (h).

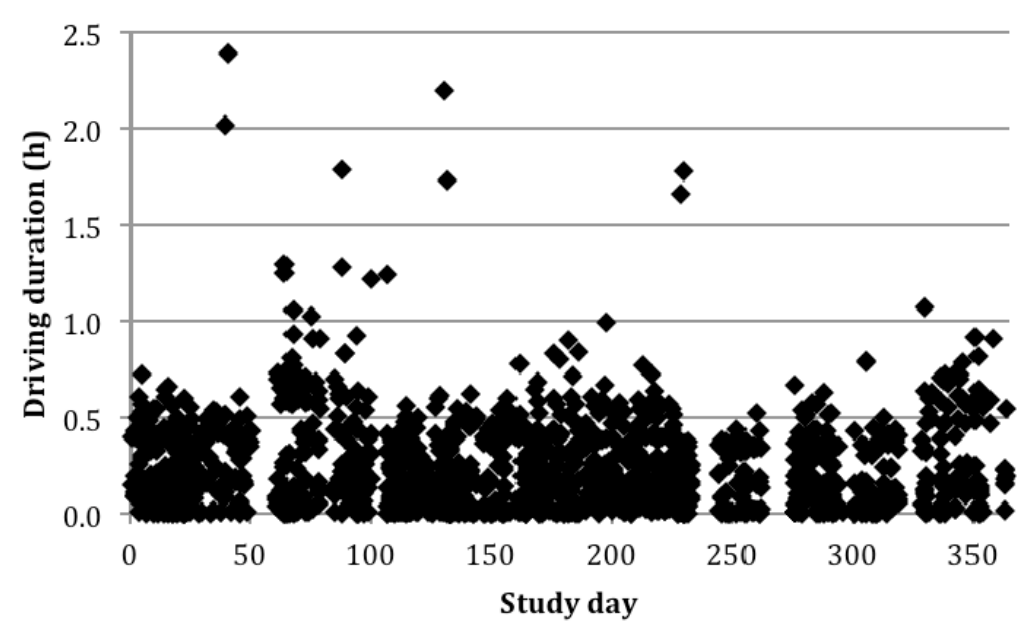


Table A-1. Daily driving distance (mi or \% of days, all days).

\begin{tabular}{|c|c|c|c|c|c|c|c|c|c|c|}
\hline & Sunday & Monday & Tuesday & Wednesday & Thursday & Friday & Saturday & Weekday & Weekend & All \\
\hline Total & 1017 & 1600 & 2048 & 1950 & 1593 & 1892 & 1209 & 9082 & 2227 & 11309 \\
\hline Ave. & 20 & 31 & 39 & 37 & 31 & 36 & 23 & 35 & 21 & 31 \\
\hline Max. & 133 & 77 & 133 & 113 & 86 & 177 & 162 & 177 & 162 & 177 \\
\hline \multicolumn{11}{|l|}{ Miles } \\
\hline $\mathbf{0}$ & $63 \%$ & $85 \%$ & $83 \%$ & $85 \%$ & $77 \%$ & $79 \%$ & $58 \%$ & $12 \%$ & & $11 \%$ \\
\hline 1 & $48 \%$ & $83 \%$ & $83 \%$ & $81 \%$ & $75 \%$ & $79 \%$ & $52 \%$ & $11 \%$ & & $10 \%$ \\
\hline 10 & $38 \%$ & $75 \%$ & $83 \%$ & $81 \%$ & $75 \%$ & $79 \%$ & $42 \%$ & $11 \%$ & & $10 \%$ \\
\hline 20 & $27 \%$ & $73 \%$ & $79 \%$ & $77 \%$ & $65 \%$ & $77 \%$ & $31 \%$ & $11 \%$ & & $9 \%$ \\
\hline 30 & $19 \%$ & $58 \%$ & $70 \%$ & $68 \%$ & $54 \%$ & $63 \%$ & $27 \%$ & $9 \%$ & & $7 \%$ \\
\hline 40 & $15 \%$ & $40 \%$ & $42 \%$ & $43 \%$ & $40 \%$ & $44 \%$ & $21 \%$ & $6 \%$ & & $5 \%$ \\
\hline 50 & $15 \%$ & $19 \%$ & $21 \%$ & $26 \%$ & $15 \%$ & $23 \%$ & $17 \%$ & $3 \%$ & & $3 \%$ \\
\hline 60 & $13 \%$ & $2 \%$ & $15 \%$ & $13 \%$ & $12 \%$ & $13 \%$ & $13 \%$ & $2 \%$ & & $2 \%$ \\
\hline 70 & $10 \%$ & $2 \%$ & $11 \%$ & $8 \%$ & $8 \%$ & $8 \%$ & $10 \%$ & $1 \%$ & & $1 \%$ \\
\hline 80 & $10 \%$ & $0 \%$ & $8 \%$ & $6 \%$ & $6 \%$ & $2 \%$ & $10 \%$ & $1 \%$ & & $1 \%$ \\
\hline 90 & $6 \%$ & $0 \%$ & $6 \%$ & $4 \%$ & $0 \%$ & $2 \%$ & $10 \%$ & $\sim 0 \%$ & & $1 \%$ \\
\hline 100 & $6 \%$ & $0 \%$ & $4 \%$ & $4 \%$ & $0 \%$ & $2 \%$ & $8 \%$ & $\sim 0 \%$ & & $\sim 0 \%$ \\
\hline 125 & $2 \%$ & $0 \%$ & $2 \%$ & $0 \%$ & $0 \%$ & $2 \%$ & $4 \%$ & $\sim 0 \%$ & & $\sim 0 \%$ \\
\hline 150 & $0 \%$ & $0 \%$ & $0 \%$ & $0 \%$ & $0 \%$ & $2 \%$ & $4 \%$ & $\sim 0 \%$ & & $\sim 0 \%$ \\
\hline 180 & $0 \%$ & $0 \%$ & $0 \%$ & $0 \%$ & $0 \%$ & $0 \%$ & $0 \%$ & $0 \%$ & & $0 \%$ \\
\hline
\end{tabular}

Figure A-2. Charging duration.

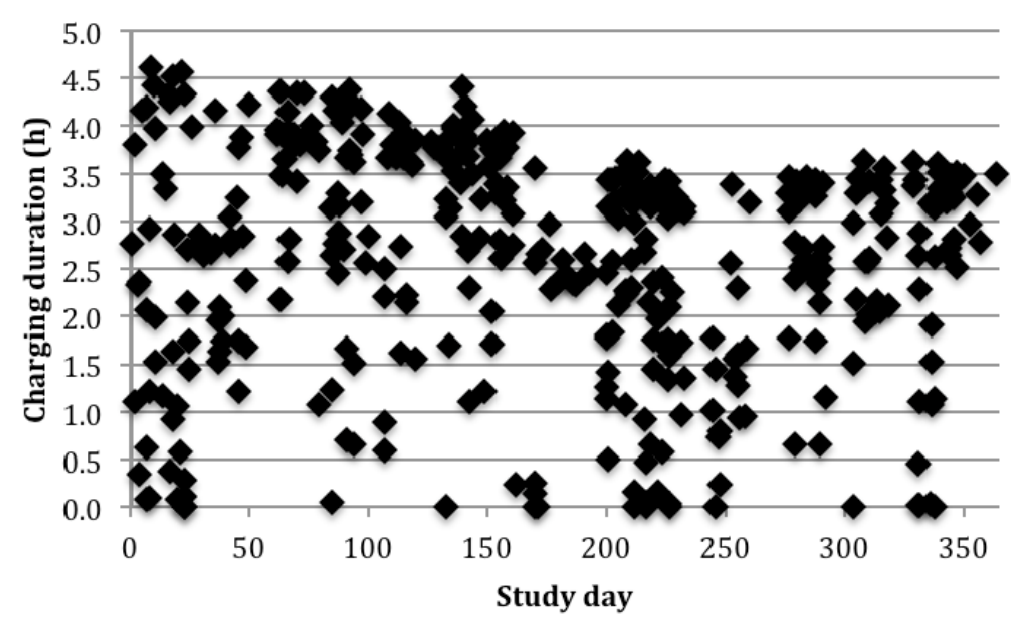

Figure A-3b is colored blue to highlight that average power is calculated by dividing the energy used during a given event by the duration of that event, as described in Section 2.4. 
Figure A-3. Charging (a) battery energy used and (b) average power.

(a)
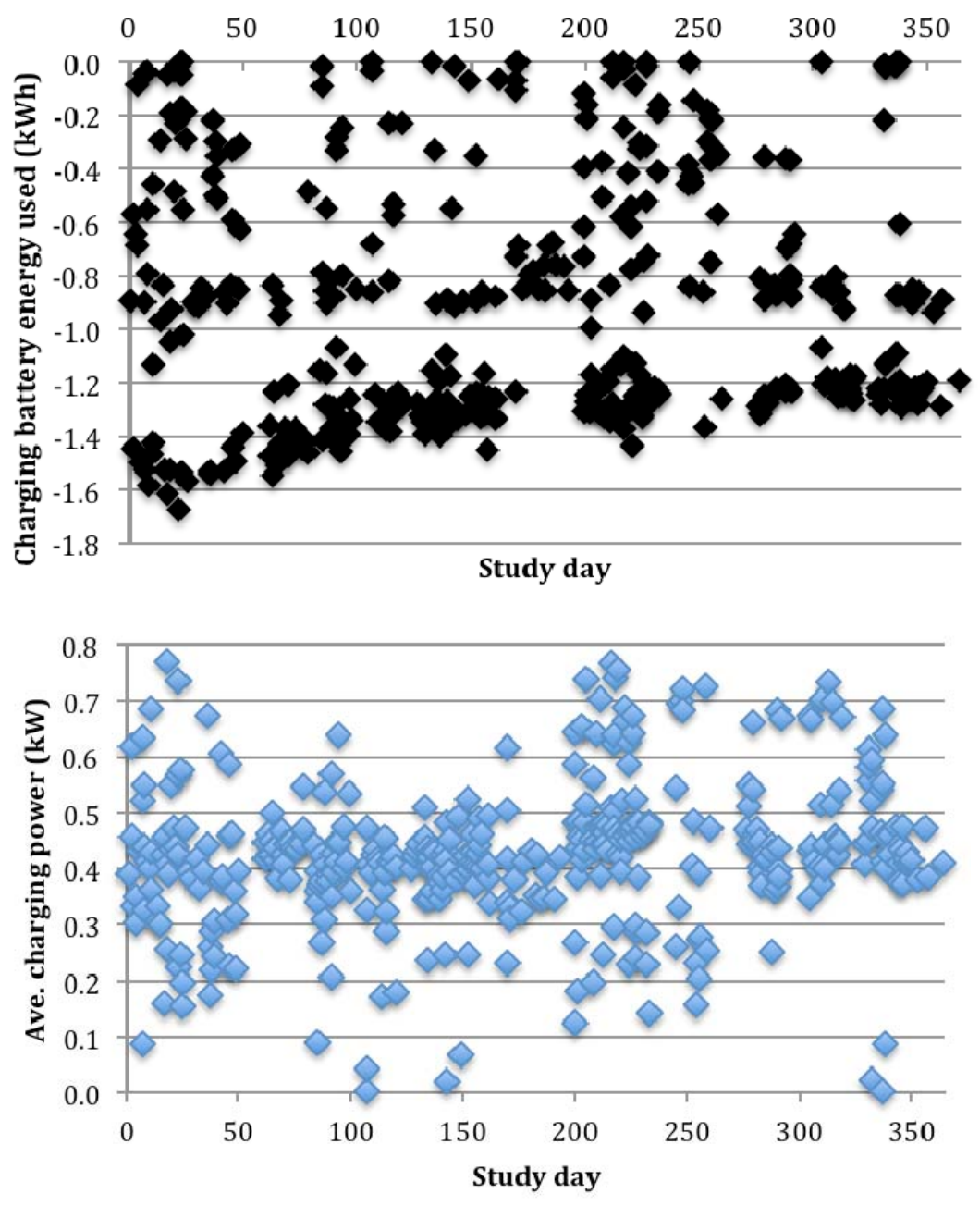

(b)

(C) 2011 by the authors; licensee MDPI, Basel, Switzerland. This article is an open access article distributed under the terms and conditions of the Creative Commons Attribution license (http://creativecommons.org/licenses/by/3.0/). 